\title{
Reducing overtopping risks in Belgian coastal towns
}

\author{
Veale William', Tomohiro Suzuki', Toon Verwaest ${ }^{1}$, Tim Spiesschaert ${ }^{1}$, Koen Trouw ${ }^{2}$ \\ and Tina Merthens ${ }^{2}$ \\ Flanders Hydraulics Research, Berchemlei 115, B-2140 Antwerp, Belgium \\ E-mail: william.veale@mow.vlaanderen.be \\ 2 Flemish Agency for Maritime and Coastal Services, Vrijhavenstraat 3, B-8400 Oostende, Belgium
}

A masterplan to strengthen weak links in the coastal defence line in Belgium was established and approved by the Flemish government in 2011 (Vlaamse Overheid, 2011). One of the measures outlined in this plan is to reduce the overtopping risk to Belgian coastal towns by introducing programs of beach nourishment and construction of wave return walls on top of existing seaside promenades. During extreme storm conditions a high, broad beach, maintained via beach nourishment, dissipates a large part of the incoming storm wave energy. The remaining wave energy reaching the coastal revetment is reflected back offshore by the wave return wall. Construction of a wave return wall on top of the seaside promenade can limit the impact of the overtopping risk to buildings and people living in coastal towns.

To test and optimise wave return wall designs, wave overtopping tests were performed in a fixed bottom physical hydraulic model at Flanders Hydraulics Research laboratory. Tests were performed at 1:25 scale in the large wave flume with dimensions $70 \mathrm{~m}$ long, $1.4 \mathrm{~m}$ high and $4 \mathrm{~m}$ wide. The foreshore profile in the scale model represents a beach profile eroded post an extreme storm event. The geometry of this eroded beach profile was estimated before construction of the physical model using the DUROSTA numerical sediment transport model.

Important processes studied with the physical hydraulic model are the transformation of waves in the breaker zone; the generation of surf-beat phenomena and their associated long wave motion on the shallow foreshore; mean and instantaneous wave overtopping; and the effect of wave return geometry at reducing impact forces and pressures on buildings to be protected behind the wave return wall.

Experimental results reveal the importance of both beach nourishment and wave return walls for safeguarding buildings and people living on seaside promenades in coastal towns. The physical model proves to be a valuable tool in the design of the coastal defence works.

In addition, data from the physical model has been used to validate a numerical model using the public domain software SWASH developed by Delft University of Technology (Zijlema et al., 2011 and Suzuki et al., 2011). Results show that the SWASH model gives excellent results regarding wave transformation on the very shallow foreshore. Wave overtopping can also be simulated with reasonable accuracy with this numerical model for wave walls with simple geometries. However, more complex wave wall geometries, such as a wave wall with a parapet or a stilling wave basin arrangement, cannot be represented well in the numerical model.

This work is co-financed by the European Union, via the Interreg IVb North Sea Region project SUSCOD (www.suscod.org). In this framework, model simulations are visualised to enable informed discussions with stakeholders so that a design which balances safety, aesthetic and practical requirements is achieved. This is a way to improve the implementation of Integrated Coastal Zone Management (ICZM) principles into practice, which is the overall goal of the SUSCOD project.

\section{References}

Suzuki T. et al. 2011 . The applicability of SWASH for modelling wave transformation and wave overtopping: a case study for the Flemish coast. Fifth Int. Conf. on Advanced COmputational Methods in ENgineering (ACOMEN).

Vlaamse Overheid. 2011 . Masterplan Kustveiligheid [Online]. Available: http://www.afdelingkust.be/nieuws.asp?TAAL_ID=1\&ITEM_L1_ID=0\&NIEUWS_ID=38

Zijlema M., G.S. Stelling and P. Smit. 2011 . SWASH: an operational public domain code for simulating wave fields and rapidly varied flows in coastal waters. Coastal Engineering 58:9921012. 